Instrumental Achievements

\title{
Purification of 2,2'-Dihydroxy-3,3',5,5',6-pentachlorobenzanilide by Counter Alternative Current Chromatography
}

\author{
Yozo KabASAWA* and Kazue TAKEBA** \\ *College of Pharmacy, Nihon University Narashinodai, Funabashi, Chiba 274, Japan \\ **The Tokyo Metropolitan Research Laboratory of Public Health, \\ Hyakunincho, Shinjuku, Tokyo 160, Japan
}

2,2'-Dihydroxy-3,3',5,5',6-pentachlorobenzanilide (OCZ) has been used for the treatment of chronic and acute fascioliasis in cattle. ${ }^{1-3}$ The high-performance liquid chromatographic analysis seems to be simple and versatile for the determination of OCZ. However, no reference standard for analysis is available. In this study, we have examined the purification of $\mathrm{OCZ}$ during preparation using Counter Alternative Current Chromatography (CACC). ${ }^{4-6}$

The most distinctive feature of the method is a system sending alternately upper and lower phases of the solvent system to the column as the mobile phase. Consequently, without a long size column, good resolution can be achieved by moving the solutes back and forth within the column assembly.

\section{Experimental}

\section{Materials and reagents}

The commercial KAMPAS was obtained from Sumitomo Chemicals Co. (Osaka, Japan. Manufactured by Imperial Chemical Industries Ltd., Pharmaceutical Division, England). The sample $\mathrm{OCZ}$ was obtained (ca. $4.7 \mathrm{~g}$ ) by dissolving $50 \mathrm{ml}$ of commercial KAMPAS in $100 \mathrm{ml}$ of $1 \mathrm{M}$ hydrochloric acid, and extracting three times with $200 \mathrm{ml}$ each of ethylacetate, then the solvent was evaporated. The sample solution saturated with sample OCZ was prepared by dissolving $500 \mathrm{mg}$ of sample $\mathrm{OCZ}$ in $20 \mathrm{ml}$ of the solvent system consisting of about equal volumes of the upper and lower phases. All other chemicals used were of reagent grade. LiChrospher RP-18 (5 $\mu \mathrm{m}, 4 \mathrm{~mm}$ i.d. $\times 250 \mathrm{~mm}$, Kanto Chemicals Co., Tokyo, Japan) was used as a separation columun.

\section{CACC apparatus}

The CACC column was made by placing 80 disks (center pinhol $1.5 \mathrm{~mm})$ in a glass tube $(12 \mathrm{~mm}$ i.d. $X$ $100 \mathrm{~cm})$ at regular intervals and connecting eight columns in series with a Teflon tube $(0.5 \mathrm{~mm}$ i.d. $)$. The solvent system used was hexane:1-butanol:ethanol: water $(10 / 3 / 10 / 10)$. In this solvent system, the distribution of $\mathrm{OCZ}$ to the upper phase was about $20 \%$. The $320 \mathrm{ml}$ upper phase and the $290 \mathrm{ml}$ lower phase were charged in eight columns, and held at $25^{\circ}$ from horizontal. The assembly was rotated at $100 \mathrm{rpm}$ and separation was made at a flow rate of $0.6 \mathrm{ml} / \mathrm{min}$.

The CACC equipment described in our previous paper ${ }^{6}$ was as follows: column holder and rotating device (Laboratory of Science and Technology, Nihon University, Tokyo, Japan), a reciprocating pump (Mini Micro Pump, Kyowa Seimitsu Co., Tokyo, Japan), a mobile phase changing device (KAM-4V, Kyowa Seimitsu Co.) and a fraction collector (Tokyo Rikakikai Co., Tokyo, Japan) equipped with a UV flow detector (NS-301, Nihon Seimitsu Kagaku Co., Tokyo, Japan), an electronic polyrecorder (EPR-100A, Toa Denpa Kogyo Co., Tokyo, Japan) and an automatic changeover switch (Tokyo Rikakikai Co.).

\section{Conditions of HPLC}

The apparatus used for HPLC was LC-6AD with a Chromatopack C-R6A (Shimadzu Seisakusho Co., Kyoto, Japan). Mobile phase was acetonitrile:0.05 M potassium dihydrogenphosphate $(\mathrm{pH} 3.0)(55 / 45)$ with a flow rate of $1 \mathrm{ml} / \mathrm{min}$. The CACC fractionized solution was evaporated and then dissolved in acetonitrile. An $20 \mu \mathrm{l}$ aliquot of this sample solution was injected into the chromatograph, monitoring was done at $218 \mathrm{~nm}$ and the purity of OCZ was determined.

\section{Purification procedure}

The sample OCZ solution was placed on the bottom of the column. The upper phase, the mobile phase, was developed from the bottom till impurities and one part of the major component (OCZ) eluted from the top of the column (Step 1). Then the lower phase was developed from the top of the column till other impurities and one part of the major component (OCZ) eluted from the bottom (Step 2), monitored by a UV detector with a polyrecorder. This procedure could be automatically changed over at a fixed value of absorbance. The upper phase was then developed again from the bottom. The procedure was alternately carried out in order to purify the OCZ in the column assembly. The eluate from the 


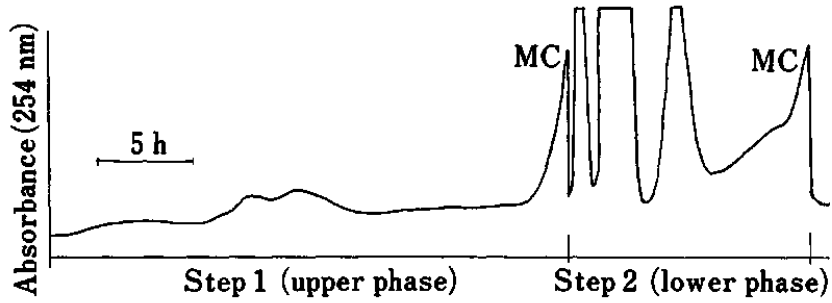

Fig. 1 Elution curve of impurities in sample OCZ by CACC. (MC) Major component (OCZ).

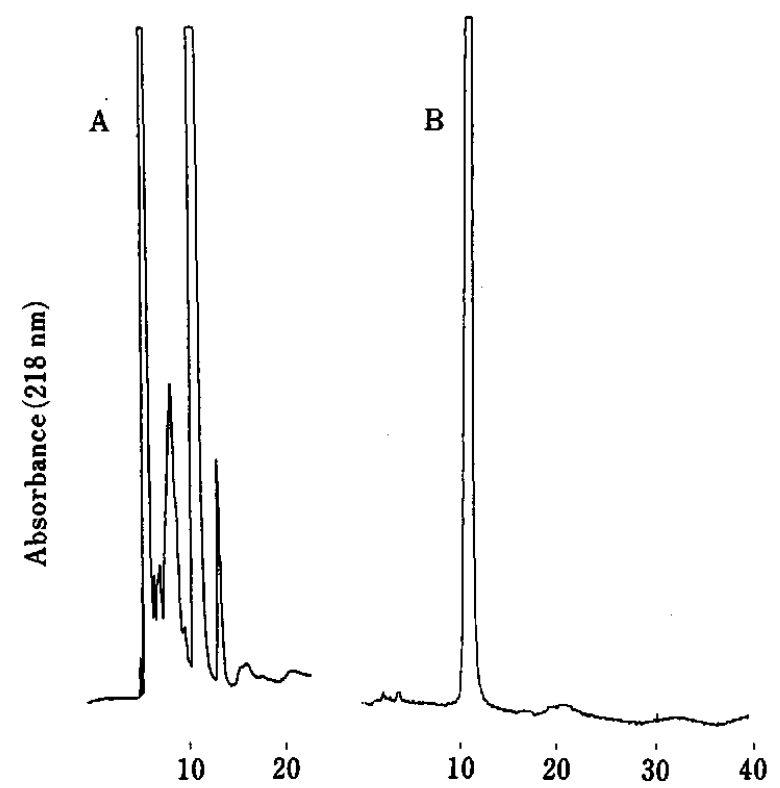

Fig. 2 HPLC chromatograms of sample $O C Z$ and purified OCZ. (A) sample OCZ; (B) purified OCZ. column was fractionized with a volume of $18 \mathrm{ml}$.

\section{Results and Discussion}

Figure 1 shows the elution profile of impurities in the sample OCZ by CACC. In step 1 , three or more minor components were eluted before OCZ. And in step 2, three peaks and one shoulder were observed on the chromatogram before elution of OCZ. As illustrated in Fig. 2 which shows HPLC chromatograms of sample $\mathrm{OCZ}$ and purified $\mathrm{OCZ}$, purified $\mathrm{OCZ}$ was obtained in step 35 by CACC, at a proportion of more than $99.8 \%$ (ca. $150 \mathrm{mg}$ ), this is usable as an analytical standard for HPLC.

The present method with used of a two phase liquidliquid system is applicable to the purification of the chemical compounds during preparation.

\section{References}

1. J. K. Walley, Vet. Rec., 78, 267 (1966).

2. J. J. Vaughan, Vet. Rec., 79, 720 (1966).

3. G. Froyd, Vet. Rec., 85, 705 (1969).

4. Y. Kabasawa, H. Nakazawa, M. Yamamoto and T. Tanimura, Bunseki Kagaku, 38, 16 (1989).

5. Y. Kabasawa, S. Kimura and T. Tanimura, Yakugaku Zasshi, 109, 168 (1989).

6. Y. Kabasawa, T. Tanimura, H. Nakazawa and $K$. Shinomiya, Anal. Sci., 8, 351 (1992).

(Received July 19, 1993) (Accepted October 8, 1993) 